Article

\title{
Double Crowding-Out Effects of Means-Tested Public Provision for Long-Term Care
}

\section{Christophe Courbage ${ }^{1, *}$ and Peter Zweifel ${ }^{2}$}

1 The Geneva Association, 53 route de Malagnou, 1208 Geneva, Switzerland

2 Emeritus, Department of Economics, University of Zurich, Kreuth 371, 9531 Bad Bleiberg, Austria; E-Mail: peter.zweifel@econ.uzh.ch

* Author to whom corresponding should be addressed;

E-Mail: christophe_courbage@genevaassociation.org; Tel.: +41-22-707-66-08.

Academic Editor: Georges Dionne

Received: 3 December 2014 / Accepted: 4 February 2015 / Published: 25 February 2015

\begin{abstract}
Publicly provided long-term care (LTC) insurance with means-tested benefits is suspected to crowd out either private saving or informal care. This contribution predicts crowding-out effects for both private saving and informal care for policy measures designed to relieve the public purse from LTC expenditure such as more stringent means testing and increased taxation of inheritance. These effects result from the interaction of a parent who decides on the amount of saving in retirement and a caregiver who decides on the effort devoted to informal care which lowers the probability of admission to a nursing home. Double crowding-out effects are also found to be the consequence of exogenous influences, notably a higher opportunity cost of caregiving.
\end{abstract}

Keywords: long-term care; crowding out; informal care; saving; means testing

\section{Introduction}

With the continuing aging of population, the demand for long-term care (LTC) services is expected to increase in nearly all industrial countries [1]. Since formal LTC services are costly, elderly citizens needing them risk ending up in poverty unless they receive support from their families or the government. However, with family members frequently unable or unwilling to provide support, governments are confronted with future increases in LTC expenditure burdening their budgets. In an 
attempt to reduce this pressure, several countries such as Austria, Germany, Japan, and Luxembourg have during the past decade implemented LTC insurance [2]. Usually contributions are not risk-rated, and benefits fall short of covering the full cost of LTC, making subsidies out of the public purse necessary. These subsidies are typically means-tested in that wealthy recipients are made to pay more towards their stay in a nursing home.

LTC insurance without risk rating was suspected of inducing moral hazard effects on the part of potential caregivers already by [3] and [4,5] because it encourages in particular spouses and children as potential caregivers to substitute formal care for their efforts. Specifically, their bequest which otherwise would be reduced by the parent's stay in a nursing home is now protected, thus undermining the effectiveness of bequests for creating incentives to provide informal LTC ${ }^{1}$.

However, as suggested by [7] for the United States, there are moral hazard effects not only on the part of children but also on the part of parents. Their incentive to accumulate wealth for financing formal LTC or to build up a bequest for inducing informal care may depend on the way the cost of their LTC will be subsidized. Indeed, [8] provide empirical evidence for a negative effect of Medicaid on saving by low-income households.

While these two crowding-out effects of public provided LTC insurance have been considered independently of one another, the aim of this paper is to consider them simultaneously. The basic hypothesis of this contribution is that in the context of LTC, the interaction between a parent and a child is subject to two-sided moral hazard effects that result in a crowding out of private saving by public means-tested LTC insurance on the part of the parent ${ }^{2}$, and of informal care by formal LTC services on the part of the child. The emphasis of this paper will be on predicting behavioral adjustments to means-tested benefits of public LTC insurance as well as purely exogenous influences that may induce double crowding-out effects by simultaneously depressing private saving and informal LTC provided by caregivers.

In view of the high degree of public involvement in most OECD countries [1], parents are assumed to be partially covered by mandatory LTC coverage, whose benefits are amalgamated with any subsidy they may receive for simplicity. This leaves room for three parameters that can be varied by policy with the aim of relieving the public purse of net LTC expenditure. First, beneficiaries may be subject to an increased degree of cost sharing. Second, means testing of LTC benefits may be made more stringent. Third, bequests may be taxed more heavily as a means to raise public finance ${ }^{3}$, as proposed e.g., in Germany [10], Switzerland [11], and the United States [12]. In addition, a country may be subject to exogenous influences such as increases in the rate of interest, in the opportunity cost of time of caregivers, in the initial wealth of the parent and the child, and in the relative price of LTC services prior to subsidization. These institutional and exogenous parameters are likely to influence both parent and caregiver behavior, potentially giving rise to double crowding-out effects.

The interaction between the parent and the child (representative of potential caregivers) is modeled as a non-cooperative game. Both parties commit ex ante, i.e., before the need for LTC services (in particular, admission to a nursing home) arises. The parent controls the amount of saving after

1 See also [6] for an analysis in terms of unstable outcomes.

2 This paper abstracts from private LTC insurance on the grounds that the market for it is very small, especially in countries that have implemented public LTC insurance.

3 Empirical evidence suggests a negative correlation between inheritance taxation and intergenerational transfers (see e.g., [9]). 
retirement, reacting to the child's effort which serves to reduce the probability of admission to a nursing home. In turn, the child decides how much informal care to provide in response to the parent's saving and hence wealth available for the bequest. Parental altruism is reflected by the fact that final wealth is bequeathed in its entirety; child altruism, by a loss of utility when the parent is in the nursing home. Policy measures and exogenous influences displace the joint optimum, making it possible to predict changes in outcomes in terms of both saving and informal care which may amount to a double crowding out.

One crucial finding is that measures designed to reduce the financial burden of publicly provided LTC (such as more stringent means testing of benefits and increased taxation of inheritance) run the distinct risk of inducing double crowding-out effects. This prediction goes beyond e.g., [7], who find that means testing of Medicaid benefits discourages parental saving but neglect the possibility of children counteracting this effect by deploying more effort, which may result in avoided admissions to or shortened stays in the nursing home. Indeed, this paper argues that less saving by parents may well combine with less effort on the part of children, constituting a warning to governments who may consider applying more stringent means testing to their LTC benefits (which are often far more generous than in the case of U.S. Medicaid). At the same time, most of them levy lower inheritance taxes than the United States and may be tempted to increase these taxes in the aim of a quid-pro-quo financing of publicly provided LTC [13]. This policy too may induce double crowding out, creating more problems than it solves. More worrying yet, double crowding out may not be the consequence of public policy but of exogenous influences such as an increased opportunity cost of caregiving on the part of children.

The remainder of this paper is structured as follows. The model is presented in Section 2. The predictions of the model in response to policy measures and exogenous influences are expounded in Section 3 . The final section is devoted to a summary and suggestions for policy and future research.

\section{The Model}

Let the parent $P$ and the potential caregiver $C$ (a child, but also a spouse, a relative or a friend) interact in the guise of non-cooperative game. First, consider the decision problem of the parent, next, that of the child.

\subsection{The Parent}

The parent is assumed to be rich enough to leave a bequest but poor enough to obtain some LTC insurance benefits which are themselves means-tested or combined with means-tested subsidies - a likely case in those countries that have introduced mandatory LTC insurance or added a LTC component to their social security. He or she decides on the propensity to save $s$ and hence the size of the bequest available to the caregiver. The caregiver (called the child henceforth) selects an amount of effort $e$ that serves to reduce the probability $\pi$ that the parent will need formal LTC services (admission to a nursing home henceforth), with $\pi^{\prime}(e)<0$ and $\pi^{\prime \prime}(e)>0$. This formulation implies that informal care has a purely preventive property; yet it is this type of effort that affects the public purse. Informal care once the parent is admitted to the nursing home improves his or her quality of life, serving to diminish the difference in utilities introduced next. The parent is characterized by a VNM utility function $u($.) 
defined over consumption in the period right after retirement, and over wealth in a future period, both of unit length ${ }^{4}$. During this second period, he or she faces the risk of spending the rest of his or her life in a nursing home. Accordingly, the parent's utility function is conditioned on being in $\left(v^{i}(\cdot)\right)$ or outside the nursing home $\left(v^{o}(\cdot)\right)$. His or her utility when out of the nursing home is higher for a given amount of wealth than when in the home, i.e., $v^{o}>v^{i}$, reflecting the greater degree of independence in the enjoyment of wealth. We assume the same ordering of marginal utilities of wealth, i.e., $v^{\prime o}>v^{\prime i}$ regardless of the difference in wealth between the two states. This assumption can be justified first in view of [14] and [15], who find empirical evidence suggesting that bad health goes along with a reduced marginal utility of wealth. Admission to a nursing home is usually caused by a deterioration of health. Second, relative risk aversion is known to strongly increase with age, especially after 65 [16]. Since admission to a nursing home goes along with a substantial fall in remaining life expectancy [17], a parent in the home can be said to be older than when continuing to live independently. Denoting $R_{R}^{i}:=\left(-u^{\prime i} / u^{i i}\right) \cdot w^{i}$ as the coefficient of relative risk aversion "when in" and $R_{R}^{o}:=\left(-u^{\prime o} / u^{\prime o}\right) \cdot w^{o}$ "when out", respectively, one therefore has $\left|\left(u^{\prime o} / u^{o}\right) \cdot w^{o}\right|<\left|\left(u^{\prime i} / u^{\prime i}\right) \cdot w^{i}\right|$. This implies $\left|\left(u^{\prime o} / w^{o}\right) / u^{\prime o}\right|>\left|\left(u^{\prime i} / w^{i}\right) / u^{\prime i}\right|$ and hence $\left.\mid u^{\prime o} / u^{\prime i}\right)|>1=|\left(u^{\prime o} w^{o}\right) /\left(u^{\prime i} w^{i}\right) \mid$, an inequality that holds unless $u^{\prime o} \ll u^{\prime \prime}$ (for which there is no particular reason) because $w^{o}>w^{i}$ in view of parental cost sharing. Accordingly, the parent is characterized by risk aversion, an assumption that holds for the child as well (see Appendix).

The parent is altruistic in the sense that final wealth $w$ becomes a bequest for the child in its entirety $^{5}$. Since the parent is assumed to be retired, there is no labor income that could contribute to wealth. Therefore, final wealth if in the nursing home is given by initial wealth saved $w_{0} s$ accrued for interest $(1+i)$ minus a share $r$ of this amount multiplied by the relative price of LTC expenditure; since time in the nursing home is normalized to one, this is the price of LTC $p$. We assume $p>1$ because nursing homes are expensive compared to the other goods and services that can be financed with wealth. The parent has to pay a share $r(w, \alpha, \beta)$ of this expense which is an increasing and convex ${ }^{6}$ function of wealth at the time of admission, reflecting the fact that LTC benefits are means-tested in most countries ${ }^{7}$ (recall that "benefits" include any subsidy the parent may receive). In addition, $\alpha$ represents an exogenous parameter reflecting an increase in the level of public support $\left(\frac{\partial r}{\partial \alpha}:=r_{\alpha}^{\prime}>0\right)$, while $\beta$ represents an increased stringency of means testing ${ }^{8}\left(\frac{\partial r_{w}^{\prime}}{\partial \beta}:=r_{w \beta}^{\prime \prime}>0\right)$. In order to distinguish

4 Contrary to the first period, the second-period utility function has wealth and not consumption as its argument in order to model the bequest motive of the parent while taking into account the fact that the bequest serves as an instrument for influencing child behavior. Introducing second-period consumption as a decision variable would complicate the analysis without producing important insights.

5 In the case of multiple siblings, it seems realistic to assume that the parent allocates, as far as he or she can, the bequest to the child who provides care.

6 Convexity reflects progressiveness of the cost-sharing schedule.

7 Means-testing in the United States (but also in Germany and Switzerland, e.g.,) includes a "look-back" period for assessing parental wealth and/or a limit on inter vivos bequests during such a period designed to avoid spend-down by parents, qualifying them for a public subsidy.

8 Stringency of means testing refers to the gradient of cost sharing w.r.t. wealth. Increased stringency therefore means that this gradient increases. 
the two changes clearly, $r_{\alpha w}^{\prime \prime}=0$ is imposed, indicating that $d \alpha>0$ amounts to a vertical shift of the cost-sharing schedule without affecting its slope. If the parent stays out of the nursing home, final wealth is simply given by $w_{0} s(1+i)$. Note that $s$ is set prior to admission to the nursing home, constituting a commitment on the part of a parent who does not change his or her lifestyle anymore. In all, one has for expected utility $(E U)$ of the parent defined over the current and the future period,

$$
\begin{aligned}
E U=u\left(w_{0}(1-s)\right)+\pi(e) v^{i}\left[w_{0} s(1+i)-r\left(w_{0} s(1+i), \alpha, \beta\right) p\right] & \\
& +(1-\pi(e)) \cup^{o}\left[w_{0} s(1+i)\right] .
\end{aligned}
$$

From Equation (1), one can derive the first-order condition (FOC) for an interior optimum with respect to the parent's propensity to save (focusing on solutions with $0<s^{*}<1$ only),

$$
\begin{aligned}
\frac{d E U}{d s} & =-w_{0} u^{\prime}(.)+\pi(e) w_{0}\left[(1+i)\left(1-r_{w}^{\prime} p\right) \cdot v^{\prime i}(.)\right]+(1-\pi(e)) w_{0}(1+i) \cdot v^{\prime o}(.) \\
& =-u^{\prime}(.)+(1+i)\left\{\pi(e)\left(1-r_{w}^{\prime} p\right) \cdot v^{\prime i}(.)+(1-\pi(e)) \cdot v^{\prime o}(.)\right\}=0
\end{aligned}
$$

after dividing by $w_{0}$, where $s^{*}$ symbolizes the solution of Equation (2).

Equation (2) can be interpreted as follows. The first term corresponds to the certain loss of utility caused by forgone consumption. The second term reflects the probability-weighted marginal benefit of additional saving in terms of wealth in the nursing home. It is positive if $r_{w}^{\prime} p<1$ or $r_{w}^{\prime}<1 / p$, respectively (recall that $p>1$ by assumption). Conversely, if means testing of LTC is very stringent ( $r_{w}^{\prime}$ close to one), this term is negative; the parent will prefer not to accumulate savings that result in a possible reduction of wealth after retirement. Note that this may be the unexpected side effect of a policy that makes cost sharing dependent on wealth, disregarding the relative price of LTC. For instance, if LTC is twice as expensive as other goods and services ( $p=2)$, a value $r_{w}^{\prime}>0.5$ suffices to induce this result. The third term is unambiguously positive, making an interior solution (which is amenable to comparative static analysis) always possible.

The next step is to derive the response of parental saving to a change in the amount of informal care provided by the child de. Maintenance of the FOC calls for the comparative statics equation

$$
\frac{\partial^{2} E U}{\partial s^{2}} d s+\frac{\partial^{2} E U}{\partial s \partial e} d e=0
$$

Noting that $\partial^{2} E U / \partial s^{2}<0$ is a second-order necessary condition for a maximum and assuming that the parent is capable of seeking out a maximum rather than a minimum of utility, one has

$$
\operatorname{sgn}\left[\frac{d s}{d e}\right]=\operatorname{sgn}\left[\frac{\partial^{2} E U}{\partial s \partial e}\right],
$$

with

$$
\frac{\partial^{2} E U}{\partial s \partial e}=\pi^{\prime}(e) w_{0}(1+i)\left(\left(1-r_{w}^{\prime} p\right) v^{\prime i}-v^{\prime o}\right)=\pi^{\prime}(e) w_{0}(1+i)\left(v^{\prime i}-v^{\prime o}-r_{w}^{\prime} p v^{\prime i}\right)>0 .
$$

Since $v^{i}<v^{\prime o}$ by assumption while $r_{w}^{\prime}>0$, the second parenthesis is negative. Due to the fact that $\pi^{\prime}(e)<0, d s / d e>0$, indicating that the parent chooses to save more in response to an increased effort on the part of the child. 


\subsection{The Child}

The child (considered as the one caregiver here) also derives utility from final wealth, which is initial wealth $z_{0}$ augmented by the bequest he or she can expect, amounting to a fraction $k(1-t)$ of the parent's final wealth. ${ }^{9}$ Here, $t$ symbolizes the rate of the tax levied on inheritance. During the first period, the child is assumed to value his or her effort with an opportunity cost $\theta$ per unit of time (the wage rate if employed). At the start of the second period, the child is assumed to enter retirement, with a concomitant drop in $\theta$. For simplicity, $\theta=0$ is assumed. In case the parent stays out of the nursing home, the bequest is larger because there is no share $r$ of the cost of LTC to be paid. Note that effort $e$ is again set during the current period as a commitment and an aspect of lifestyle, not to be adjusted anymore in future, regardless of whether the parent is in or out of the nursing home. Therefore, expected utility of the child $(E \bar{U})$ reads,

$$
\begin{aligned}
E \bar{U}=\bar{u}\left(z_{0}-\theta e\right)+\pi(e) \bar{v}^{i}\left[z_{0}+k(1-t)\left\{w_{0} s(1+i)-r\left(w_{0} s(1+i), \alpha, \beta\right) p\right\}\right] & \\
& +(1-\pi(e)) \bar{v}^{o}\left[z_{0}+k(1-t)\left\{w_{0} s(1+i)\right\}\right] .
\end{aligned}
$$

Here, $\bar{u}($.$) is the child's VNM utility function defined over net wealth in the current period, while$ $\bar{v}^{i}(\cdot)$ symbolizes utility in the future period given that the parent is in the nursing home and $\bar{v}^{o}($. otherwise, with $\bar{v}^{o}>\bar{v}^{i}$ and $\bar{v}^{\prime o}>\bar{v}^{\prime i}$ for a given amount of wealth. Therefore, the child is altruistic to the extent that he or she derives more utility as well as marginal utility from a given amount of wealth if the parent is out of the nursing home. This reflects increased enjoyment of consumption with a parent who is independent (on a vacation, e.g.,).

The FOC is given by

$$
\frac{d E \bar{U}}{d e}=-\theta \bar{u}^{\prime}(\cdot)+\pi^{\prime}(e)\left(\bar{v}^{i}(\cdot)-\bar{v}^{o}(\cdot)\right)=0
$$

with $e^{*}$ denoting the solution of Equation (4). The first term mirrors the certain utility loss associated with additional effort. It is balanced by the decreased probability of having the parent in the nursing home times the associated utility loss. Note that an interior solution $e^{*}>0$ is obtained only if $\bar{v}^{o}>\bar{v}^{i}$.

From Equation (5), we thus have at the optimum that $\bar{v}^{o}>\bar{v}^{i}$ regardless of the difference in wealth between the two states. In order to maintain this inequality when child's wealth increases, $\bar{v}^{\prime o}>\bar{v}^{\prime i}$ is required regardless of the difference in wealth between the two states.

In analogy to Equation (5), the child's response to a change in the parent's saving propensity satisfies

$$
\operatorname{sgn}\left[\frac{d e}{d s}\right]=\operatorname{sgn}\left[\frac{\partial^{2} E \bar{U}}{\partial e \partial s}\right]
$$

From Equation (4), one obtains

9 For simplicity, we abstract from the fact that in some countries (notably Germany), the child may be called upon to contribute to the cost of LTC, resulting in a deduction from $z_{0}$ that depends on $z_{0}$ (means testing) and $p$. Also, the model is in terms of one parent and one child; otherwise, the optimal allocation of both bequest and caring effort between the surviving spouse and the children would have to be determined. 


$$
\frac{\partial^{2} E \bar{U}}{\partial e \partial s}=\pi^{\prime}(e) k w_{0}(1+i)\left(\bar{v}^{\prime i}-\bar{v}^{\prime o}-r_{w}^{\prime} p \bar{v}^{\prime i}\right)>0
$$

Thus, the child is predicted to increase his or her optimal effort in response to increased parental saving.

\section{Predictions of the Model}

The interaction of parent and child is modeled as a Nash equilibrium, i.e., a joint optimum of the two decision-makers. In this section, a total of eight exogenous changes displacing this equilibrium are analyzed. Three changes reflect a policy which aims to decrease the net financial burden of public provision of LTC, namely an increase in cost sharing $(d \alpha>0$, with $\partial r / \partial \alpha>0)$, more stringent testing of public LTC benefits ( $d \beta>0$, with $\left.\partial r_{w}^{\prime} / \partial \beta>0\right)$, and an increase in the taxation of inheritance $(d t>0$, with $\partial k(1-t) / \partial t=-\partial k / \partial t<0)$ which causes a decrease in the net bequest the potential caregiver can look forward to. Five changes are exogenous to a country's LTC policy; these are an increase in the nominal rate of interest $(d i>0)$, in the wage rate of the child $(d \theta>0)$, in the initial wealth of the parent $\left(d w_{0}>0\right)$ and of the child $\left(d z_{0}>0\right)$, and in the relative price of LTC services $(d p>0)$.

In order to determine the displacement of the Nash equilibrium caused by an exogenous change denoted by $d \rho$, the adjustments of the two decision variables $s$ and $e$ need to be derived. They follow from two simultaneous comparative statics equations analogous to Equation (3) above,

$$
\left(\begin{array}{cc}
\frac{\partial^{2} E U}{\partial s^{2}} & \frac{\partial^{2} E U}{\partial s \partial e} \\
\frac{\partial^{2} E \bar{U}}{\partial e \partial s} & \frac{\partial^{2} E \bar{U}}{\partial e^{2}}
\end{array}\right)\left(\begin{array}{l}
d s \\
d e
\end{array}\right)=-\left(\begin{array}{c}
\frac{\partial^{2} E U}{\partial s \partial \rho} \\
\frac{\partial^{2} E \bar{U}}{\partial e \partial \rho}
\end{array}\right) d \rho, \text { with } \rho=\alpha, \beta, t, \theta ; i, w_{0}, z_{0}, p .
$$

Using Cramer's rule, one obtains

$$
\frac{d s}{d \rho}=\frac{1}{X}\left|\begin{array}{cc}
-\frac{\partial^{2} E U}{\partial s \partial \rho} & \frac{\partial^{2} E U}{\partial s \partial e} \\
-\frac{\partial^{2} E \bar{U}}{\partial e \partial \rho} & \frac{\partial^{2} E \bar{U}}{\partial e^{2}}
\end{array}\right| \text { and } \frac{d e}{d \rho}=\frac{1}{X}\left|\begin{array}{cc}
\frac{\partial^{2} E U}{\partial s^{2}} & -\frac{\partial^{2} E U}{\partial s \partial \rho} \\
\frac{\partial^{2} E \bar{U}}{\partial e \partial s} & -\frac{\partial^{2} E \bar{U}}{\partial e \partial \rho}
\end{array}\right|
$$

with $X$ denoting the determinant of the Hessian matrix on the right-hand side of Equation (10). On the assumption introduced above that the two decision-makers can tell a maximum from a minimum, the Hessian is negative definite for a maximum, implying that $X$ is positive. Therefore, the displacement of the Nash equilibrium is given in qualitative terms by:

$$
\begin{gathered}
\operatorname{sgn}\left(\frac{d s}{d \rho}\right)=\operatorname{sgn}\left(-\frac{\partial^{2} E U}{\partial s \partial \rho} \frac{\partial^{2} E \bar{U}}{\partial e^{2}}+\frac{\partial^{2} E \bar{U}}{\partial e \partial \rho} \frac{\partial^{2} E U}{\partial s \partial e}\right) \\
\operatorname{sgn}\left(\frac{d e}{d \rho}\right)=\operatorname{sgn}\left(-\frac{\partial^{2} E U}{\partial s^{2}} \frac{\partial^{2} E \bar{U}}{\partial e \partial \rho}+\frac{\partial^{2} E \bar{U}}{\partial e \partial s} \frac{\partial^{2} E U}{\partial s \partial \rho}\right) \text { with } \rho=\alpha, \beta, t, \theta, w_{0}, z_{0}, p .
\end{gathered}
$$

Computational details are provided in the Appendix. The results are presented in Table 1 below.

As to increased cost sharing in expenditure on LTC services (No. 1 in Table 1), this measure either crowds in informal care, with ambiguous effect on private parental saving if lenient means testing of public LTC benefits $\left(r_{w}^{\prime} p<1\right)$, or crowds in saving, with ambiguous effect on child effort if stringent 
means testing $\left(r_{w}^{\prime} p>1\right)$. The intuition is that now the threat of having to pay an increased part of LTC expenditure while making the parent save more, may still cause the bequest the child is looking forward to be lower, thus undermining his or her incentive to provide care.

Double crowding out in the sense of a lower propensity to save on the part of the parent combined with less informal care provided by the child is a distinct possibility according to the model presented here. It is predicted for the other two measures designed to relieve the public purse, i.e., more stringent means testing (No. 2) and increased inheritance taxation (No. 3). Intuitively, these measures undermine the parent's motivation to preserve wealth, which in turn weakens the child's incentive to provide informal care rather than relying on formal LTC services.

Table 1. Predicted instances of crowding out.

\begin{tabular}{|c|c|c|c|c|}
\hline \multirow{2}{*}{ Policy Measures } & \multicolumn{2}{|c|}{$\begin{array}{c}\text { Lenient Means Testing } \\
r_{w}^{\prime} p<1\end{array}$} & \multicolumn{2}{|c|}{$\begin{array}{c}\text { Stringent Means Testing } \\
\qquad r_{w}^{\prime} p>1\end{array}$} \\
\hline & $\begin{array}{c}\text { Private Saving } \\
\qquad d s<0\end{array}$ & $\begin{array}{c}\text { Informal Care } \\
\qquad e<0\end{array}$ & $\begin{array}{c}\text { Private Saving } \\
\qquad d s<0\end{array}$ & $\begin{array}{c}\text { Informal Care } \\
d e<0\end{array}$ \\
\hline 1. Increased cost sharing $(d \alpha>0, \partial r / \partial \alpha>0)$ & $?$ & yes & yes & $?$ \\
\hline 2. More stringent means testing $\left(d \beta>0, \partial r_{w}^{\prime} / \partial \beta>0\right)$ & yes & yes & yes & yes \\
\hline 3. Increased taxation of inheritance $(d t>0)$ & yes & yes & yes & yes \\
\hline \multicolumn{5}{|l|}{ Exogenous influences } \\
\hline 4. Higher initial wealth of the parent $\left(d w_{0}>0\right)$ & $?$ & $?$ & yes & $?$ \\
\hline 5. Higher relative price of LTC services $(d p>0)$ & $?$ & $?$ & $?$ & $?$ \\
\hline 6. Higher nominal rate of interest $(d i>0)$ & $?$ & $\stackrel{?}{?}$ & no ${ }^{a, b}$ & yes $^{c}$ \\
\hline 7. Higher initial wealth of the child $\left(d z_{0}>0\right)$ & $\mathrm{No}^{\mathrm{a}}$ & $\mathrm{No}^{\mathrm{a}}$ & $\mathrm{No}^{\mathrm{a}}$ & $\mathrm{No}^{\mathrm{a}}$ \\
\hline 8. Higher opportunity cost of the child $(d \theta>0)$ & yes & yes & yes & yes \\
\hline
\end{tabular}

${ }^{\mathrm{a}}$ Beneficial crowding-in effect; ${ }^{\mathrm{b}}$ If $w_{0}$ or $s \rightarrow 0$, otherwise: ? ${ }^{\mathrm{c}}$ If $w_{0}$ large, otherwise: ?

In addition, there are influences that are typically regarded as being exogenous to LTC policy. Higher parental wealth (No. 4) has ambiguous effects given lenient means testing.

Under stringent means testing, it does crowd out parental saving, with an ambiguous effect on child effort. A higher relative price of LTC services (prior to the public subsidy) has ambiguous effects given both lenient and stringent means testing (No. 5). Intuitively, while this creates pressure on the parent to come up with additional savings, it is unclear whether final wealth will be higher given admission to a nursing home. This uncertainty undermines the child's incentive to provide care which is strengthened, however, by the consideration that the higher price of care is irrelevant if the parent stays out of the nursing home. A higher nominal rate of interest (No. 6) constitutes another change beyond the purview of LTC policy. It leads to ambiguous effects if means testing is lenient but mixed effects if it is stringent. It crowds in saving by the parent when his or her wealth or propensity to save is low. However, it crowds out child effort if parental wealth is high. This is an instance where a development on the capital market in conjunction with the seemingly harsh policy of stringent means testing can be of partial benefit to the poor and while hurting the rich.

Turning to exogenous influences that primarily affect the child, higher initial wealth (No. 7) leads to the one case of a double crowding in of both parental saving and child effort regardless of stringency 
of means testing. Conversely, higher opportunity cost of time on the part of child (No. 8) gives rise to another double crowding-out effect regardless of stringency of means testing, which is not surprising.

When it comes to actual behavior, developments in Germany are instructive. There, social health insurance was complemented by mandatory LTC coverage in 1995. Initially, the contribution rate was 0.4 percent of payroll; at the time of writing (2014), it stands at 1.95 percent - a fourfold increase that dwarfs the increase of healthcare expenditure in general. The picture is completed by increases in the number of nursing homes by 24.5 percent and their capacity, by 24 percent, respectively between 1999 and 2007 [18]. While these developments cannot directly be attributed to a combination of less informal caregiving by children and less saving by parents, they are certainly suggestive of strong moral hazard effects.

\section{Conclusion and Outlook}

Publicly provided LTC insurance and subsidization of the cost of LTC have been suspected to crowd out private saving [8,19] and [3,5]. However, these contributions do not show that a double crowding out may be the simultaneous outcome of the interaction of the two players. They also neglect that means-testing of public LTC benefits typically is a matter of degree. The purpose of this paper is to fill these gaps by modeling a parent who decides about his or her propensity to save in response to the child's amount of caregiving, and a child who decides about his or her caregiving in response to the parent's propensity to save which affects the size of the bequest.

Three policy measures designed to decrease the net financial burden of public provision of LTC are analyzed, viz. an increase in the cost share borne by the parent as the beneficiary, more stringent means testing of LTC benefits, and an increased taxation of inheritance. Regardless of the initial stringency of means testing, double crowding-out effects are predicted for the last two measures, according to the model presented here. Increased cost sharing constitutes the one exception, having an ambiguous effect on parental saving combined with reduced child effort if means testing was lenient initially, and an ambiguous effect on child effort combined with a depression of parental saving if it was stringent. These results point to serious challenges that are confronting public policy. Making wealthy elderly people contribute to the cost of LTC in a more progressive way appears an easy way to relieve the public purse from the high cost of LTC, while taxing bequests more highly is seen as an easy way to boost revenue of government revenue generally. Both alternatives have the potential of undermining not only private saving on the part of citizens who might need formal LTC services in the future but also provision of informal care on the part of children, relatives, and friends serving as a substitute especially of costly nursing home care.

In addition, influences largely beyond government's control may create additional challenges to public policy. Among the five exogenous influences considered, only a higher opportunity cost on the part of the child (indicated by the attainable wage rate) is predicted to have a double crowding-out effect regardless of stringency of means testing. In particular, women have been enjoying greatly improved opportunities in the labor market in the past, causing their opportunity cost of caregiving to increase. There is every reason to expect this trend to extend into the future. Moreover, given stringent means testing, a higher initial wealth of the parent may crowd out private saving, while a higher nominal rate of interest may have the unexpected side effect of crowding out informal care provided to wealthy parents. 
There are several limitations of this analysis that need to be pointed out. First, the two players may be more altruistic than modeled here. For instance, the parent could suffer a utility loss from the opportunity cost of caring borne by the child, while the child could also derive utility from being with the parent. Second, the model may be extended to comprise three generations, with ambiguous effects however. On the one hand, the child may also anticipate his or her own old age, serving to weaken any moral hazard effect with respect to effort. On the other hand, the caregiver may have children of his or her own, causing his or her opportunity cost of time to be particularly high. This would reinforce moral hazard effects. Another potential shortcoming is that the two decision variables are fixed prior to the possible admission to the nursing home. A more refined analysis would introduce parental saving before and after admission and an effort level before and after admission on the part of the caregiver. In the latter case, the two variables could be interpreted in different ways, i.e., actual effort designed to keep the parent out of the nursing home and simply time spent with him or her. Also, both the objectives and functional relationships may have to be specified differently, depending on whether the caregiver is a child, the spouse, or a friend, all of whom have inheritance prospects that are subject to differing legal norms. As a first approximation, these norms are reflected in changes in the parameter $k$. Finally, the case of multiple siblings whose decisions could interact has not been taken into account in order to avoid a complication that is unlikely to add much insight to public policy.

In spite of these limitations, some of the crucial insights of this research are likely to be robust. One is that for establishing any crowding-out effect (single or double) of public LTC coverage and subsidization, the interaction between the beneficiary and the caregiver needs to be studied. In addition, the stringency of means testing of public LTC support is of considerable importance for predicting the outcome of this interaction. Along with other policy measures and exogenous influences, it constitutes a crucial determinant of the possible occurrence of a double crowding-out effect, namely the decrease of private saving combined with less provision of informal LTC.

\section{Acknowledgments}

The authors are grateful to two anonymous referees for their comments and criticisms.

\section{Author Contributions}

Christophe Courbage and Peter Zweifel contributed equally to the conception, findings and writing of the paper.

\section{Appendix}

The purpose of this Appendix is to derive the eight predictions listed in Table 1. Note that risk aversion of the two actors is assumed throughout. The point of departure is Equation (12), which is repeated for convenience,

$$
\begin{aligned}
& \operatorname{sgn}\left(\frac{d s}{d \rho}\right)=\operatorname{sgn}\left(-\frac{\partial^{2} E U}{\partial s \partial \rho} \frac{\partial^{2} E \bar{U}}{\partial e^{2}}+\frac{\partial^{2} E \bar{U}}{\partial e \partial \rho} \frac{\partial^{2} E U}{\partial s \partial e}\right) \\
& \operatorname{sgn}\left(\frac{d e}{d \rho}\right)=\operatorname{sgn}\left(-\frac{\partial^{2} E U}{\partial s^{2}} \frac{\partial^{2} E \bar{U}}{\partial e \partial \rho}+\frac{\partial^{2} E \bar{U}}{\partial e \partial s} \frac{\partial^{2} E U}{\partial s \partial \rho}\right)
\end{aligned}
$$


with $\rho=\alpha, \beta, t ; i, \theta, w_{0}, z_{0}, p$.

For the common elements, one has from Equation (5)

$$
\frac{\partial^{2} E U}{\partial s \partial e}>0
$$

and from Equation (9),

$$
\frac{\partial^{2} E \bar{U}}{\partial e \partial s}>0
$$

Moreover,

$$
\begin{aligned}
\frac{\partial^{2} E U}{\partial s^{2}} & =w_{0}^{2} u^{\prime \prime}-\pi(e)\left(w_{0}(1+i)\right)^{2} p r_{w}^{\prime \prime} v^{\prime i}+\pi(e)\left(w_{0}(1+i)\left(1-r_{w}^{\prime} p\right)\right)^{2} v^{\prime i} \\
& +(1-\pi(e))\left(w_{0}(1+i)\right)^{2} v^{\prime \prime}<0
\end{aligned}
$$

as $r_{w}^{\prime \prime}>0$ (progressiveness of cost-sharing schedule) and

$$
\begin{aligned}
& \frac{\partial^{2} E \bar{U}}{\partial e^{2}}=\theta^{2} \bar{u}^{\prime \prime}+\pi^{\prime \prime}(e)\left(\bar{v}^{i}-\bar{v}^{o}\right)<0 \\
& \text { as } \pi "(e)>0 .
\end{aligned}
$$

The remaining terms of Equation (A.1) are parameter-specific.

1. Increase in Cost Sharing $(d \alpha>0)$

From Equations (1) and (2),

$$
\begin{aligned}
& \frac{\partial^{2} E U}{\partial s \partial \alpha}=-(1+i) \pi(e)\left(1-r_{w}^{\prime} p\right) r_{\alpha}^{\prime} p v^{\prime \prime i} \\
& >0 \text { if } r_{w}^{\prime} p<1 \quad \text { (lenient means testing) } \\
& <0 \text { if } r_{w}^{\prime} p>1 \text { (stringent means testing) }
\end{aligned}
$$

From Equations (6) and (7), one has

$$
\frac{\partial^{2} E \bar{U}}{\partial e \partial \alpha}=\pi^{\prime}(e) k(1-t)\left(-r_{\alpha}^{\prime} p\right) \bar{v}^{\prime i}<0
$$

Therefore, Equations (A.2), (A.5), (A.6), and (A.7) result in

$$
\begin{aligned}
\operatorname{sgn} & \left(\frac{d s}{d \alpha}\right)=\operatorname{sgn}\left(-\frac{\partial^{2} E U}{\partial s \partial \alpha} \frac{\partial^{2} E \bar{U}}{\partial e^{2}}+\frac{\partial^{2} E \bar{U}}{\partial e \partial \alpha} \frac{\partial^{2} E U}{\partial s \partial e}\right) \\
& <0 \text { if } r_{w}^{\prime} p<1 \text { (lenient means testing) } \\
& <0 \text { if } r_{w}^{\prime} p>1 \text { (stringent means testing) }
\end{aligned}
$$

Also, Equations (A.3), (A.4), (A.6), and (A.7) yield

$$
\operatorname{sgn}\left(\frac{d e}{d \alpha}\right)=\operatorname{sgn}\left(-\frac{\partial^{2} E U}{\partial s^{2}} \frac{\partial^{2} E \bar{U}}{\partial e \partial \alpha}+\frac{\partial^{2} E \bar{U}}{\partial e \partial s} \frac{\partial^{2} E U}{\partial s \partial \alpha}\right)
$$


Risks 2015, 3

$$
\begin{aligned}
& <0 \text { if } r_{w}^{\prime} p>1 \text { (lenient means testing) } \\
& <0 \text { if } r_{w}^{\prime} p>1 \text { (stringent means testing) }
\end{aligned}
$$

2. More Stringent Means Testing $(d \beta>0)$

From Equations (2) and (1), one obtains

$$
\frac{\partial^{2} E U}{\partial s \partial \beta}=(1+i) \pi(e)\left(-r_{w \beta}^{\prime \prime} p\right) v^{\prime i}<0
$$

As to the child, Equations (6) and (7) reveal that an increase in $\beta$ does not affect $d E \bar{U} / d e$,

$$
\frac{\partial^{2} E \bar{U}}{\partial e \partial \beta}=0
$$

Therefore, Equations (A.5) and (A.11) imply

$$
\operatorname{sgn}\left(\frac{d s}{d \beta}\right)=\operatorname{sgn}\left(-\frac{\partial^{2} E U}{\partial s \partial \beta} \frac{\partial^{2} E \bar{U}}{\partial e^{2}}+\frac{\partial^{2} E \bar{U}}{\partial e \partial \beta} \frac{\partial^{2} E U}{\partial s \partial e}\right)=\operatorname{sgn}\left(\frac{\partial^{2} E \bar{U}}{\partial e \partial \beta} \frac{\partial^{2} E U}{\partial s \partial e}\right)<0
$$

Because of (A.3), (A.12), and (A.13),

$$
\operatorname{sgn}\left(\frac{d e}{d \beta}\right)=\operatorname{sgn}\left(-\frac{\partial^{2} E U}{\partial s^{2}} \frac{\partial^{2} E \bar{U}}{\partial e \partial \beta}+\frac{\partial^{2} E \bar{U}}{\partial e \partial s} \frac{\partial^{2} E U}{\partial s \partial \beta}\right)=\operatorname{sgn}\left(\frac{\partial^{2} E \bar{U}}{\partial e \partial s} \frac{\partial^{2} E U}{\partial s \partial \beta}\right)<0
$$

3. Increased Taxation of Inheritance $(d t>0)$

In view of Equations (2) and (1) it is clear that $d E U / d s$ is not affected, hence

$$
\frac{\partial^{2} E U}{\partial s \partial t}=0
$$

Moreover, Equations (6) and (7) imply

$$
\frac{\partial^{2} E \bar{U}}{\partial e \partial t}=\pi^{\prime}(e)\left[k w_{0} s(1+i)\left(\bar{v}^{\prime 0}-\bar{v}^{\prime i}\right)+k r\left(w_{0} s(1+i), \alpha, \beta\right) p \bar{v}^{\prime i}\right]<0
$$

since $\pi^{\prime}(e)<0$ and $\bar{v}^{\prime 0}>\bar{v}^{\prime i}$.

Therefore, Equations (A.4), (A.14), and (A.15), and yield

$$
\operatorname{sgn}\left(\frac{d s}{d t}\right)=\operatorname{sgn}\left(-\frac{\partial^{2} E U}{\partial s \partial t} \frac{\partial^{2} E \bar{U}}{\partial e^{2}}+\frac{\partial^{2} E \bar{U}}{\partial e \partial t} \frac{\partial^{2} E U}{\partial s \partial e}\right)=\operatorname{sgn}\left(\frac{\partial^{2} E \bar{U}}{\partial e \partial t} \frac{\partial^{2} E U}{\partial s \partial e}\right)<0
$$

In view of Equations (A.4), (A.3), (A.14), and (A.15), one has

$$
\operatorname{sgn}\left(\frac{d e}{d t}\right)=\operatorname{sgn}\left(-\frac{\partial^{2} E U}{\partial s^{2}} \frac{\partial^{2} E \bar{U}}{\partial e \partial t}+\frac{\partial^{2} E \bar{U}}{\partial e \partial s} \frac{\partial^{2} E U}{\partial s \partial t}\right)=\operatorname{sgn}\left(-\frac{\partial^{2} E U}{\partial s^{2}} \frac{\partial^{2} E \bar{U}}{\partial e \partial t}\right)<0
$$

4. Higher Initial Wealth of the Parent $\left(d w_{0}>0\right)$

Derivation of Equation (2) yields in view of Equation (1),

$$
\frac{\partial^{2} E U}{\partial s \partial w_{0}}=-(1-s) u^{\prime \prime}+s(1+i)\left\{\pi(e)\left[-r_{w}^{\prime \prime} p v^{\prime i}+\left(1-r_{w}^{\prime} p\right)^{2} v^{\prime \prime i}\right]+(1-\pi(e)) v^{\prime \prime 0}\right\}<0
$$


in view of e.g., Halek and Eisenhower (2001) who find that risk aversion increases with age (in particular after retirement), making it realistic to assume $u^{\prime \prime}$ small compared to $v^{\prime \prime i}$ and $v^{\prime \prime 0}$.

As to the child,

$$
\begin{aligned}
\frac{\partial^{2} E \bar{U}}{\partial e \partial w_{0}} & =\pi^{\prime}(e)\left\{\left[k(1-t) s(1+i)-k(1-t) r_{w}^{\prime} s(1+i) p\right] \cdot \bar{v}^{\prime i}(\cdot)-k(1-t) s(1+i) \cdot \bar{v}^{\prime o}(\cdot)\right\} \\
& =\pi^{\prime}(e) k(1-t) s(1+i)\left\{\left(1-r_{w}^{\prime} p\right) \cdot \bar{v}^{\prime i}(\cdot)-\bar{v}^{\prime o}(\cdot)\right\} \\
& <0 \text { if } r_{w}^{\prime} p<1 \text { (lenient means testing) } \\
& >0 \text { if } r_{w}^{\prime} p>1 \text { (stringent means testing) since } \bar{v}^{\prime i}(\cdot)>\bar{v}^{\prime o}(\cdot)
\end{aligned}
$$

Using Equations (A.2), (A.5), (A.18), and (A.19), this implies

$$
\begin{aligned}
\operatorname{sgn}( & \left.\frac{d s}{d w_{0}}\right)=\operatorname{sgn}\left(-\frac{\partial^{2} E U}{\partial s \partial w_{0}} \frac{\partial^{2} E \bar{U}}{\partial e^{2}}+\frac{\partial^{2} E \bar{U}}{\partial e \partial w_{0}} \frac{\partial^{2} E U}{\partial s \partial e}\right) \\
& <0 \text { if } r_{w}^{\prime} p<1 \text { (lenient means testing) } \\
& <0 \text { if } r_{w}^{\prime} p>1 \text { (stringent means testing) }
\end{aligned}
$$

Moreover, in view of Equations (A.3), (A.4), (A.18), and (A.19), one obtains

$$
\operatorname{sgn}\left(\frac{d e}{d w_{0}}\right)=\operatorname{sgn}\left(-\frac{\partial^{2} E U}{\partial s^{2}} \frac{\partial^{2} E \bar{U}}{\partial e \partial w_{0}}+\frac{\partial^{2} E \bar{U}}{\partial e \partial s} \frac{\partial^{2} E U}{\partial s \partial w_{0}}\right)>0
$$

5. Higher Relative Price of LTC Services $(d p>0)$

From Equations (1) and (2), one obtains for the parent

$$
\begin{aligned}
\frac{\partial^{2} E U}{\partial s \partial p}=(1+i) & \pi(e)\left(-r_{w}^{\prime}\right) v^{\prime i}+(1+i)\left(1-r_{w}^{\prime} p\right) r\left(w_{0} s(1+i), \alpha, \beta\right) v^{\prime \prime i} \\
& <0 \text { if } r_{w}^{\prime} p<1 \text { (lenient means testing) } \\
& <0 \text { if } r_{w}^{\prime} p>1 \text { (stringent means testing) }
\end{aligned}
$$

Turning to the child, Equations (6) and (7) imply

$$
\frac{\partial^{2} E \bar{U}}{\partial e \partial p}=-\pi^{\prime}(e) k(1-t) r(\cdot) \cdot \bar{v}^{i^{\prime}}(\cdot)>0 .
$$

Therefore, one has from Equations (A.2), (A.5), (A.22), and (A.23),

$$
\operatorname{sgn}\left(\frac{d s}{d p}\right)=\operatorname{sgn}\left(-\frac{\partial^{2} E U}{\partial s \partial p} \frac{\partial^{2} E \bar{U}}{\partial e^{2}}+\frac{\partial^{2} E \bar{U}}{\partial e \partial p} \frac{\partial^{2} E U}{\partial s \partial e}\right)>0
$$

and from Equations (A.3), (A.4), (A.22), and (A.23),

$$
\operatorname{sgn}\left(\frac{d e}{d p}\right)=\operatorname{sgn}\left(-\frac{\partial^{2} E U}{\partial s^{2}} \frac{\partial^{2} E \bar{U}}{\partial e \partial p}+\frac{\partial^{2} E \bar{U}}{\partial e \partial s} \frac{\partial^{2} E U}{\partial s \partial p}\right)>0
$$

6. Higher Nominal Rate of Interest $(d i>0)$

As to the parent, Equations (1) and (2) yield 


$$
\begin{gathered}
\frac{\partial^{2} E U}{\partial s \partial i}=\pi(e)\left(1-r_{w}^{\prime} p\right) v^{\prime i}+(1-\pi(e)) v^{\prime 0}+(1+i)\left\{\pi(e)\left(1-r_{w}^{\prime} p\right)^{2} w_{0} s v^{\prime \prime i}\right. \\
\left.+(1-\pi(e)) w_{0} s v^{\prime \prime 0}-\pi(e) w_{0} s r_{w}^{\prime} p v^{\prime i}\right\}
\end{gathered}
$$

Using the FOC in Equation (2) to obtain $\pi(e)\left(1-r_{w}^{\prime} p\right) \cdot v^{\prime i}()+.(1-\pi(e)) \cdot v^{\prime o}()=.u^{\prime}() /.(1+i)$, this simplifies to

$$
\begin{aligned}
& \frac{\partial^{2} E U}{\partial s \partial i}=u^{\prime}+w_{0} s\{\pi(e)\left.\left(1-r_{w}^{\prime} p\right)^{2} v^{\prime \prime i}+(1-\pi(e)) v^{\prime \prime 0}-\pi(e) r_{w}^{\prime} p v^{\prime i}\right\} \\
&>0 \text { if } w_{0} \text { or } s \rightarrow 0 \\
&<0 \text { if } w_{0} \text { large } .
\end{aligned}
$$

As to the child, Equations (6) and (7) imply

$$
\begin{aligned}
\frac{\partial^{2} E \bar{U}}{\partial e \partial i}= & \pi^{\prime}(e) k(1-t) w_{0} s\left[\left(1-r_{w}^{\prime} p\right) \cdot \bar{v}^{i^{\prime}}(\cdot)-\bar{v}^{o^{\prime}}(\cdot)\right] \\
& >0 \text { if } r_{w}^{\prime} p<1 \text { (lenient means testing) } \\
& >0 \text { if } r_{w}^{\prime} p>1 \text { (stringent means testing) }
\end{aligned}
$$

Therefore, in view of Equations (A.3), (A.5), (A.26), and (A.27),

$$
\begin{aligned}
& \operatorname{sgn}\left(\frac{d s}{d i}\right)=\operatorname{sgn}\left(-\frac{\partial^{2} E U}{\partial s \partial i} \frac{\partial^{2} E \bar{U}}{\partial e^{2}}+\frac{\partial^{2} E \bar{U}}{\partial e \partial i} \frac{\partial^{2} E U}{\partial s \partial e}\right) \\
& <0 \text { if lenient means testing or } w_{0} \text { large } \\
& >0 \text { if stringent means testing and } w_{0} \text { or } s \rightarrow 0
\end{aligned}
$$

In addition, Equations (A.3), (A.4), (A.26), and (A.27) yield

$$
\begin{aligned}
& \operatorname{sgn}\left(\frac{d e}{d i}\right)=\operatorname{sgn}\left(-\frac{\partial^{2} E U}{\partial s^{2}} \frac{\partial^{2} E \bar{U}}{\partial e \partial i}+\frac{\partial^{2} E \bar{U}}{\partial e \partial s} \frac{\partial^{2} E U}{\partial s \partial i}\right) \\
< & 0 \text { if } r_{w}^{\prime} p<1 \text { (lenient means testing) } \\
< & 0 \text { if } r_{w}^{\prime} p>1 \text { (stringent means testing) and } w_{0} \text { large }
\end{aligned}
$$

7. Higher Initial Wealth of the Child $\left(d z_{0}>0\right)$

In view of Equations (1) and (2), it is evident that

$$
\frac{\partial^{2} E U}{\partial s \partial z_{0}}=0
$$

Moreover,

$$
\frac{\partial^{2} E \bar{U}}{\partial e \partial z_{0}}=-\theta \bar{u}^{\prime \prime}(\cdot)+\pi^{\prime}(e)\left(\bar{v}^{i^{\prime}}(\cdot)-\bar{v}^{o^{\prime}}(\cdot)\right)<0
$$

since $\pi^{\prime}(e)$ and $\bar{v}^{\prime i}(\cdot)>\bar{v}^{\prime o}(\cdot)$.

Using Equations (A.2), (A.30), and (A.31) one has 


$$
\operatorname{sgn}\left(\frac{d s}{d z_{0}}\right)=\operatorname{sgn}\left(-\frac{\partial^{2} E U}{\partial s \partial z_{0}} \frac{\partial^{2} E \bar{U}}{\partial e^{2}}+\frac{\partial^{2} E \bar{U}}{\partial e \partial z_{0}} \frac{\partial^{2} E U}{\partial s \partial e}\right)=\operatorname{sgn}\left(\frac{\partial^{2} E \bar{U}}{\partial e \partial z_{0}} \frac{\partial^{2} E U}{\partial s \partial e}\right)>0
$$

and in view of Equations (A.5), (A.30), and (A.31),

$$
\operatorname{sgn}\left(\frac{d e}{d z_{0}}\right)=\operatorname{sgn}\left(-\frac{\partial^{2} E U}{\partial s^{2}} \frac{\partial^{2} E \bar{U}}{\partial e \partial z_{0}}+\frac{\partial^{2} E \bar{U}}{\partial e \partial s} \frac{\partial^{2} E U}{\partial s \partial z_{0}}\right)=\operatorname{sgn}\left(-\frac{\partial^{2} E U}{\partial s^{2}} \frac{\partial^{2} E \bar{U}}{\partial e \partial z_{0}}\right)>0
$$

\section{Higher Opportunity Cost of the Child $(d \theta>0)$}

As can be gleaned from Equations (1) and (2), this does not affect the parent in this model, thus

$$
\frac{\partial^{2} E U}{\partial s \partial \theta}=0
$$

As far as the child is concerned, Equations (6) and (7) yield

$$
\frac{\partial^{2} E \bar{U}}{\partial s \partial \theta}=-\bar{u}^{\prime}+\theta e \bar{u}^{\prime \prime}<0
$$

Therefore, one obtains in view of Equations (A.2), (A.34), and (A.35),

$$
\operatorname{sgn}\left(\frac{d s}{d \theta}\right)=\operatorname{sgn}\left(-\frac{\partial^{2} E U}{\partial s \partial \theta} \frac{\partial^{2} E \bar{U}}{\partial e^{2}}+\frac{\partial^{2} E \bar{U}}{\partial e \partial \theta} \frac{\partial^{2} E U}{\partial s \partial e}\right)=\operatorname{sgn}\left(\frac{\partial^{2} E \bar{U}}{\partial e \partial \theta} \frac{\partial^{2} E U}{\partial s \partial e}\right)<0
$$

and in view of Equations (A.5), (A.35), and (A.34),

$$
\operatorname{sgn}\left(\frac{d e}{d \theta}\right)=\operatorname{sgn}\left(-\frac{\partial^{2} E U}{\partial s^{2}} \frac{\partial^{2} E \bar{U}}{\partial e \partial \theta}+\frac{\partial^{2} E \bar{U}}{\partial e \partial s} \frac{\partial^{2} E U}{\partial s \partial \theta}\right)=\operatorname{sgn}\left(-\frac{\partial^{2} E U}{\partial s^{2}} \frac{\partial^{2} E \bar{U}}{\partial e \partial \theta}\right)<0
$$

\section{Conflicts of Interest}

The authors declare no conflict of interest.

\section{References}

1. Colombo, F.; Llena-Nozal, A.; Mercier, J.; Tjadens, F. Help Wanted? Providing and Paying for Long-Term Care; OECD Health Policy Studies; OECD: Paris, France, 2011.

2. Colombo, F.; Mercier, J. Help wanted? Fair and sustainable financing of long-term care services. Appl. Econ. Perspect. Policy 2012, 34, 316-332.

3. Pauly, M.V. The rational non-purchase of long-term care insurance. J. Polit. Econ. 1990, 95, 153-168.

4. Zweifel, P.; Strüwe, W. Long-term care insurance and bequests as instruments for shaping intergenerational relationships. J. Risk Uncertain. 1996, 12, 65-76.

5. Zweifel, P.; Strüwe, W. Long-term care insurance in a two generation model. J. Risk Insur. 1998, $65,33-56$.

6. Courbage, C.; Zweifel, P. Two-sided intergenerational moral hazard, long-term care insurance, and nursing home use. J. Risk Uncertain. 2011, 43, 65-80.

7. Brown, J.; Finkelstein, A. The interaction of public and private insurance: Medicaid and the long-term care insurance market. Am. Econ. Rev. 2008, 98, 1083-1102. 
8. Gruber, J.; Yelowitz, A. Public health insurance and private saving. J. Polit. Econ. 1999, 107, 1249-1274.

9. Jappelli, T.; Padula, M.; Pica, G. Do transfer taxes reduce intergenerational transfers? J. Eur. Econ. Assoc. 2014, 12, 248-275.

10. Houben, H.; Maiterith, R. Erbschaftssteuer und Erbschaftssteuerreform in Deutschland-eine Bestandesaufnahme (Inheritance Taxation and Its Reform in Germany-The state of Affairs); Verlag Duncker \& Humblot: Berlin, Germany, 2011; pp. 161-188.

11. Popular initiative "Erbschaftssteuerreform" ("Reform of inheritance tax"), 2013. Available online: http://www.erbschafts-steuerreform.ch (accessed on 5 February 2015).

12. Obama to Propose a Tax Increase on Investments, Inherited Property, 17 Jan. Available online: http://www.wsj.com/articles/obama-to-propose-tax-hikes-on-investments-inheritedproperty-1421542876 (accessed on 5 February 2015).

13. International Comparison of Australia's Taxes, 2006. Available online: http://comparative taxation.treasury.gov.au (accessed on 1 February 2014).

14. Evans, W.N.; Viscusi, W.K. Estimation of state dependent utility function using survey data. Rev. Econ. Stat. 1991, 73, 94-104.

15. Finkelstein, A.; Luttmer, E.; Notowidigdo, M. Approaches to estimating the health state dependence of the utility function. Am. Econ. Rev. 2009, 99, 116-121.

16. Halek, M.; Eisenhower, G.M. Demography and risk aversion. J. Risk Insur. 2001, 68, 1-24.

17. Zweifel, P.; Felder, S.; Meier, M. Ageing of population and health care expenditure: A red herring? Health Econ. 1999, 8, 485-496.

18. Rothgang, H. Vor- und Nachteile der Versicherungsmethode der Finanzierung von Langzeitpflege am Beispiel Deutschlands (Advantages and downsides of financing long-term care through insurance, using Germany as the example). In Proceedings of the 12th International Thorner Konferenz für Lanzeitpflege, Torun, Poland, 21-22 September 2009.

19. Sloan, F.A.; Norton E.C. Adverse selection, bequests, crowding out, and private demand for insurance: Evidence from the long-term care insurance market. J. Risk Uncertain. 1997, 15, 201-219.

(C) 2015 by the authors; licensee MDPI, Basel, Switzerland. This article is an open access article distributed under the terms and conditions of the Creative Commons Attribution license (http://creativecommons.org/licenses/by/4.0/). 